\title{
Consubstanciação da imagem da Embrapa no campo científico*
}

\author{
Uajará Pessoa Araújo** \\ Luiz Marcelo Antonialli*** \\ Mozar José de Brito**** \\ Almiralva Ferraz Gomes***** \\ Renato Ferreira de Oliveira******
}

SumÁRIo: 1. Introdução; 2. Referencial teórico e revisão da literatura; 3. Método da pesquisa; 4. Resultados e discussão; 5. Conclusão.

Summary: 1. Introduction; 2. Theoretical framework and literature review; 3. Method of research; 4. Results and discussion; 5 . Conclusion.

Palavras-chave: campo científico; P\&D na agropecuária; Bourdieu.

KEY woRDs: scientific field; agricultural R\&D; Bourdieu.

\footnotetext{
* Artigo recebido em set. 2010 e aceito em jan. 2011.

** Doutor em administração e em engenharia da produção. Professor do Centro Federal de Educação Tecnológica de Minas Gerais (Cefet-MG). Endereço: Cefet-MG, Campus II, Av. Amazonas, 7675 - Nova Gameleira - CEP 30510-000, Belo Horizonte, MG, Brasil. E-mail: uajara@yahoo. com.br.

*** Doutor em administração. Professor da Universidade Federal de Lavras (Ufla). Endereço: Ufla, Campus Universitário, Caixa Postal 3037 - CEP 37200-000, Lavras, MG, Brasil. E-mail: lmantonialli@uol.com.br.

**** Doutor em administração. Professor da Universidade Federal de Lavras (Ufla). Endereço: Ufla, Campus Universitário, Caixa Postal 3037 - CEP 37200-000, Lavras, MG, Brasil. E-mail: mozarjdb@ufla.br.

$* * * * *$ Doutora em administração. Professora da Universidade Estadual do Sudoeste da Bahia (Uesb). Endereço: Uesb, Campus de Vitória da Conquista, Estrada do Bem-Querer, km 4 - Bairro Universitário - CEP 45083-900, Vitória da Conquista, BA, Brasil. E-mail: almiralva@gmail. com.

$* * * * * * *$ Mestre em zootecnia. Professor do Instituto Federal de Educação, Ciência e Tecnologia Sul de Minas Gerais (Ifet). Endereço: Ifet Sul de Minas Gerais, Campus Machado, Rodovia MachadoParaguaçu, km 3 - Santo Antônio - CEP 37750-000, Machado, MG, Brasil. E-mail: renatofo@ eafmachado.gov.br.
} 
O campo científico da agropecuária é objeto do estudo que tem como objetivo investigar a construção da posição dominante ocupada pela Embrapa entre as entidades que se voltam para esse domínio do saber e trazer algumas inferências. Na consecução desses propósitos, optou-se por empregar métodos bibliométricos e sociométricos para uma leitura inscrita no paradigma positivista, considerando-o mais próximo aos cientistas que compõem o campo em evidência, convidando-os à reflexão e facilitando-a ao utilizar métodos de mesma natureza de suas pesquisas. As evidências coletadas parecem indicar que a projeção da Embrapa não restou explicada por mérito científico, o que implicou a necessidade de esquadrinhar explicações alternativas, quando se buscou em Bourdieu ferramental para a tarefa. Conclui-se que a Embrapa é central no campo estudado ao cuidar em projetar uma imagem, tão real quanto de fato, à medida que não é contestada além de reclamos não sistematizados e que dispensam dados objetivos — situação que por si mesma provoca outro questionamento, também encaminhado na pesquisa.

\section{Embrapa image substantiation in the scientific field}

The agricultural scientific field is the object of this study, which aims to investigate the construction of the dominant position occupied by Embrapa between those who turn to this field of knowledge and to formulate some inferences. In achieving these purposes, we chose to use bibliometric and sociometric methods for a reading in a positivist paradigm approach, considering it as more friendly to the scientists in the agricultural field, asking them to reflect, facilitating it by using methods of the same nature as their research. The evidence collected suggests that the projection of Embrapa is not explained by scientific merit, which meant the need to probe alternative explanations, when we employed the concepts of Bourdieu for the task. We conclude that Embrapa is central in the scrutinized field in caring for the projection of an image, as real as it is, as long as it is not contested beyond non-systematized claims and those which dispense with objective data - which in itself cause further questioning, also referred to in this research.

\section{Introdução}

Uma apresentação da Empresa Brasileira de Pesquisa Agropecuária (Embrapa), tida como a principal instituição em pesquisas voltadas para a agricultura tropical (Fuck et al., 2007), foi apropriada de referência provida pelo Ministério da Agricultura, Pecuária e Abastecimento (Mapa):

Reconhecida como uma das grandes responsáveis pelo aumento da produção brasileira de grãos, que atingiu 9,5\% em 2003, a Embrapa lidera o Sistema Nacional de Pesquisa Agropecuária (SNPA). Essa rede engloba, além das unidades de pesquisa e desenvolvimento da empresa, centros de pesquisa agropecuária 
estaduais, algumas universidades brasileiras e outras instituições privadas. [...] De acordo com especialistas da área, a Embrapa desenvolve $52 \%$ dos projetos em agricultura no Brasil. Governos estaduais contribuem com 20\%. Universidades, com 21\% (Brasil, 2009).

O texto oferece algumas premissas que foram inicialmente tomadas como verdadeiras: 1) a relevância da pesquisa agropecuária brasileira; 2) a existência de um sistema de pesquisa; e, finalmente, 3) a posição dominante da Embrapa, por mérito científico e por delegação, como coordenadora do SNPA. Testar a premissa 3 foi, a princípio, motivado por mero cuidado acadêmico: afinal, o número de projetos não deveria ser o indicador exclusivo de competência em pesquisa.

Para tanto, a escolha do foco desta pesquisa considerou que a pauta agropecuária brasileira é composta de 64 itens com relevância econômica, mas é concentrada, por ordem, nos seguintes produtos: soja, cana, pecuária, milho, café e laranja - que, em conjunto, respondem por dois terços do valor da produção agropecuária do país, que, por sua vez, responde por $6 \%$ do Produto Interno Bruto (PIB, dados de 2008, segundo o Instituto Brasileiro de Geografia e Estatística, 2009).

Daí, para efeito dessa investigação, optou-se por duas das áreas relevantes do setor: café e soja, que respondem em conjunto por um quarto do valor da produção agropecuária brasileira (Instituto..., 2009). Soja por ser a cultura de maior peso e café por ter sido seu Consórcio de Pesquisa, coordenado pela Embrapa, motivo de pesquisa recente (Araújo, 2008) e os dados dessa pesquisa estarem disponíveis. Um terceiro estudo contemplando a pesquisa em pecuária leiteira já está em andamento. Tais estudos são complementares e destinam-se a oferecer uma composição entre outras possíveis, visando o entendimento da rede, dos pesquisadores e da pesquisa agropecuária no Brasil.

Voltando-se para as pesquisas de café e de soja e vencida a primeira etapa, confirmatória ou, mais apropriadamente, não se rejeitando a premissa 3, poder-se-ia encaminhar o estudo para sua questão primária: a repercussão do modelo de gestão da entidade central sobre os demais agentes, imersos no campo e submetidos a outras lógicas.

No entanto, a premissa 3 não resistiu inabalável ao teste proposto. As evidências não se prestaram para corroborar a existência de coordenação no SNPA. Como também não legitimaram a proposição de diferencial acadêmico do pesquisador da Embrapa diante de seus parceiros e concorrentes na Universidade Federal de Lavras (Ufla), na Universidade Federal de Viçosa (UFV), na Escola Superior de Agricultura Luiz de Queiroz (Esalq/USP) e na Univer- 
sidade Estadual Paulista Júlio de Mesquita Filho (Unesp). Se esse achado for tomado como válido e extensível para as demais culturas, e considerando que a fração de pesquisadores da Embrapa sobre o total de pesquisadores no campo científico agropecuário não ultrapassa $20 \%$ (mais provável, algo próximo a 15\%), esse seria o limite superior da importância acadêmica da Embrapa, considerando o conjunto de culturas e disciplinas.

A menos que trabalhos ulteriores levem à reformulação do patamar mencionado, depara-se com uma questão não prevista no planejamento inicial do estudo: a projeção da Embrapa sobre o campo científico agropecuário brasileiro é questionável? Se não, como explicar sua construção? E qual o impacto desse fenômeno?

Este artigo apresenta o esforço realizado para encaminhar tais inquietações. Partiu-se da revisão bibliográfica tratando o campo científico e os trabalhos voltados para discutir o papel da Embrapa no campo da pesquisa agropecuária. A revisão é apresentada na seção 2 . A seção 3 foi reservada para descrição do método utilizado na investigação, mais descritiva que explicativa, mormente quantitativa, inscritível no paradigma positivista, que lançou mão de instrumentos sociométricos e bibliométricos, complementados com dados secundários de outros autores e pela análise de conteúdo de entrevistas junto a pesquisadores do campo.

Como ponto de partida, admitiu-se que: 1) os periódicos científicos se prestam a indicar a produção em uma dada área do saber; 2) as coautorias em artigos publicados em periódicos científicos são indicadores de ligações de pesquisa entre os pesquisadores; e, 3) essas ligações, mais ou menos estáveis, configuram a rede social científica de tais pesquisadores, explicitadas pela sociometria. A sociometria toma ontologicamente a sociedade como uma estrutura objetiva de indivíduos e suas ligações. Para estudar esse arranjo, a sociometria se baseia em quatro pontos: perspectiva estruturalista voltada para as ligações entre atores sociais; suportada pelo acúmulo de dados empíricos; submetidos a modelos matemáticos e computacionais; e representados em gráficos, ditos sociogramas (Freeman, 2004).

A bibliometria vem sendo aceita há algum tempo como ferramenta útil em estudos no campo da ciência \& tecnologia. No Brasil, a própria Embrapa tem sido motivo de estudos bibliométricos por pesquisadores de seu quadro (Guedes et al., 2008; Luiz e Bitencourt, 2008; Penteado et al., 2002, 2007), o que dá sustentação adicional ao emprego do método diante da questão proposta.

Os resultados da aplicação dessas técnicas e da análise de alguns dados secundários complementares são apresentados na seção 4, arrematada com algumas reflexões à guisa de conclusão na última seção. 


\section{Referencial teórico e revisão da literatura}

A proposta de campo científico de P. Bourdieu (2004) oferece algumas conjecturas úteis que foram acolhidas no desenvolvimento dessa investigação, que lançou mão ainda do poder disciplinar de M. Foucault (1977) em seu embasamento teórico, ainda suplementado com a revisão de trabalhos que tomam a Embrapa como objeto de estudo.

\subsection{Campo e capital científico}

P. Bourdieu (2004) desenvolveu sua teoria de campo e a aplicou em artes, literatura, jornalismo e ciência - essa já em 1975, discutindo a especificidade do campo científico e as condições sociais do progresso da razão. Vinte anos mais tarde, revisitou seus conceitos amoldando-os ao campo de pesquisa agropecuária - no caso, francesa - o que tornou tal trabalho especialmente atrativo.

Para Bourdieu (2004:20-21) o campo designa um espaço do cosmo social que se destaca por ser-lhe relativamente autônomo, dotado de leis sociais próprias. O grau de autonomia seria indicado pela resistência: pelos mecanismos que o campo aciona para se libertar de imposições externas e ter condições de reconhecer apenas suas determinações internas. No caso de autonomia absoluta, configurar-se-ia a ciência pura, livre de qualquer necessidade social. No oposto, encontrar-se-ia a ciência escrava, sujeita a todas as demandas político-econômicas. Esses tipos ideais fugiriam da realidade, pois as pressões externas existem e repercutem no campo, mas esse é capaz de "refratá-las", de internalizá-las obedecendo à sua lógica (do campo). Quanto mais autônomo o campo, maior seu poder de refração, mais as imposições externas são transfiguradas e menos fica sujeito à "politização".

Mas todo campo seria também um campo de forças e um campo de lutas para conservar ou transformar esse campo de forças, onde somente poder-seia entender as ações de um agente se for identificada a posição que tal agente ocupa na estrutura, ou, mais precisamente, a quantidade relativa de seu capital científico em um dado momento, que proporciona autoridade ao agente dominante para definir as regras do jogo e da apropriação dos resultados.

Segundo Bourdieu (2004:35-42), o capital científico seria um tipo específico de capital simbólico composto de duas parcelas: 1 ) aquele consistido pelo crédito atribuído pelo conjunto de pares-concorrentes (capital por prestígio); e 2) aquele ligado à ocupação de posições de caráter burocrático e político, portanto, de poder - intrusão que tem sua gênese na cessão de parte da 
autonomia do campo, devido a sua necessidade de financiamento para cobrir o custo da ciência (capital institucionalizado). ${ }^{1}$ Nessa composição de capital científico, seria difícil o acúmulo simultâneo das duas parcelas e, portanto, é de esperar detentores de um forte crédito científico e de frágil peso político, bem como detentores de forte peso político e de frágil crédito científico - mas, uma vez acumulado, as duas dimensões poderiam interagir e poderia haver conversão entre os capitais de prestígio e institucionalizado, de pesos relativos dependentes do grau de autonomia do campo (alta autonomia, maior peso para o capital de prestígio; baixa autonomia, para o capital institucionalizado).

Outro ponto em Bourdieu de especial interesse é seu questionamento sobre o argumento da "demanda social", que seria inspirada

menos numa preocupação real em satisfazer as necessidades e as expectativas de tal ou qual categoria de "clientes" (grandes ou pequenos agricultores, indústrias agroalimentícias, organizações agrícolas, ministérios etc.), ou mesmo em ganhar assim seu apoio, do que assegurar uma forma relativamente indiscutível de legitimidade e, simultaneamente, um acréscimo de força simbólica nas lutas internas de concorrência pelo monopólio da definição legítima da prática científica (Bourdieu, 2004:47).

Para além do conflito pesquisa básica versus pesquisa aplicada, que na maior parte das vezes se caracterizariam em um continuum, Bourdieu (2004:54) destaca a convivência em uma mesma entidade - no caso, o Institut National de la Recherche Agrononomique (Inra) - de duas funções: a invenção (descoberta, dimensão científica) e a inovação (novos produtos e lucros no mundo econômico, dimensão econômica) regida pela lógica de uma instituição pública, liberada da pressão direta do mercado (Bourdieu, 2004:55).

Transladar tais considerações sobre o instituto francês para a empresa brasileira se apresentou útil à investigação da última, como empreendido a seguir, logo após uma breve incursão ao poder disciplinar de Foucault (1977).

\subsection{Poder disciplinar}

Foucault (1977) discutiu as relações de poder na sociedade. Parte das suas propostas - o poder disciplinar - foi utilizada como uma perspectiva

\footnotetext{
${ }^{1}$ Competência para emitir editais, participação em conselhos e em comissões.
} 
para o entendimento das ações empreendidas pela Embrapa junto a seus pesquisadores.

Observa-se que as organizações, mormente as empresas, como tal, se sentem propelidas a controlar o trabalho para extrair o maior valor possível em prol da satisfação de seus objetivos e metas. Não o fazem apenas controlando o resultado do processo, mas buscam assegurá-lo, definindo os procedimentos e escalando, habilitando, estimulando, individualizando e tornando visíveis as pessoas que se prestam ao trabalho. Todo um aparato racional-burocrático é utilizado, buscando incutir a docilidade na pessoa, configurando-se na aplicação do poder disciplinar. O corpo dócil seria aquele que pode ser submetido e utilizado, transformado e aperfeiçoado, tornando-se eficiente para a produção: a disciplina ensejaria o controle temporal e minucioso do corpo, realizando a sujeição constante de suas forças, impondo-lhe uma relação docilidade/utilidade. Daí a disciplina ser uma tecnologia positiva do exercício do poder, um conjunto de táticas, um mecanismo estratégico a partir do qual se efetivam as relações de poder. O poder disciplinar apresentar-se-ia como um sistema integrado, capaz de exercer a vigilância hierárquica, o exame e a sansão, que torna as pessoas em indivíduos visíveis, diferenciáveis, capazes de serem classificados e punidos (ou premiados). Os mecanismos da disciplina destacando cada indivíduo elaboram sua história e a arquivam, distribuem-no no espaço de forma particularizada, determinam suas atividades, controlam e relacionam seu tempo e o combinam com outros indivíduos (Silveira, 2005).

A vigilância induziria a consciência de se estar visível, o que por si só já enseja mudança no comportamento e torna o emprego de sansões menos necessário (Foucault, 1977). Contudo, para Foucault, onde há poder, há resistência - de tal forma que os choques entre o poder e a resistência criariam novas configurações dinâmicas de poder (Cappelle, Melo e Brito, 2004).

No universo acadêmico, uma manifestação do poder disciplinar seria a apuração quantitativa da produção dos pesquisadores, que os converte em objetos destacados e classificados: pesquisador sem bolsa de produtividade e com bolsa de produtividade, impondo-lhes um conceito de eficiência na pesquisa. Contudo, se, para Foucault (1977), à aplicação do poder disciplinar cabe uma ação (mais apropriadamente, uma reação) do sujeitado, tal ação pode ser apreciada no depoimento modelar colhido por Araújo (2008):

Pesquisadora A01: A avaliação numérica, tá sendo péssima. A gente tá perdendo qualidade. O que interessa é volume. Isso aí tá sendo... tá tendo um impacto ruim. Pros nossos estudantes, inclusive. Os meninos já aprendendo a dividir um trabalho em dez e não repartir com o colega dele, entendeu?... Tá criando jovens, éh, ime- 
diatistas e individualistas. Imediatista no sentido de que "Eu vou trabalhar com... alface, porque eu faço dez trabalhos num ano. Se eu for trabalhar com... sei lá — jacarandá — vou fazer um na vida. De jeito nenhum! Num consigo mestrado.” Entendeu? São umas coisas que... num sei como a gente vai arrumar não.

No exemplo, a reação ao poder disciplinar se manifesta por artifícios que introduzem novos elementos que ameaçam a pretensa racionalização inicial. Todavia, a reação se dá de diversas formas como indicadas na seção seguinte, que explora os mecanismos racionais burocráticos utilizados pela Embrapa para disciplinar o trabalho de seus pesquisadores.

\subsection{A gestão da ciência \& tecnologia na Embrapa}

A Embrapa é uma empresa pública, criada em 1972 e instalada em 1973, dotada de personalidade jurídica de direito privado, com patrimônio próprio e autonomia administrativa e financeira. Tem sede e foro em Brasília e conta com 41 unidades distribuídas em diversos estados no país, empregando 8,5 mil pessoas, entre elas 2,2 mil pesquisadores - 3/4 dos quais, doutores. Apresenta-se como tendo a missão de viabilizar soluções de pesquisa, desenvolvimento e inovação para a sustentabilidade da agricultura, em benefício da sociedade brasileira (Embrapa, 2009a), dispondo de orçamento superior a 1 bilhão de reais.

Além de executar pesquisa, a Embrapa teria a competência legal para coordenar o SNPA, composto pela própria Embrapa, mais as 17 Organizações Estaduais de Pesquisa Agropecuária (Oepas), diversas universidades brasileiras, órgãos estaduais e municipais ligados à agropecuária e entidades do setor privado. ${ }^{2}$

Desde 1988, a Embrapa lança mão da gestão estratégica, materializada em Planos Diretores da Embrapa (PDE). O I PDE, referente a 1988-92, teve por objetivo a modernização do modelo de gerenciamento da Embrapa e culminou na criação do Sistema Embrapa de Planejamento (SEP), em 1992. O II PDE, de 1994 a 1998, redefiniu a missão e os objetivos e estabeleceu novas diretrizes da empresa. O III PDE, de 2000 a 2003, trouxe consigo o Modelo de Gestão Estratégica (MGE), baseado no balanced scorecard (BSC), que levou a

\footnotetext{
${ }^{2}$ Ressalta-se que o parágrafo único do artigo 11 da Lei no 8.171 , de 17 de janeiro de 1991, determina que o SNPA se dê em convênio entre a Embrapa e um outro ente. Portanto, uma pesquisa seria do SNPA se essa se desse sob o império de um convênio com a Embrapa. A mesma Lei no 8.171 coloca em capítulos separados a pesquisa (capítulo 4) e a assistência técnica e a extensão rural (capítulo 5). O SNPA atende exclusivamente à pesquisa.
} 
Embrapa a desenvolver e a valorizar indicadores de desempenho e substituir o SEP pelo Sistema Embrapa de Gestão (SEG), em 2002. Nesse ínterim, a Embrapa, em detrimento do modelo funcional, se propôs a adotar a arquitetura organizada por processo, considerando-a mais compatível com os novos modos de construção do conhecimento (Guedes, 2001).

O IV PDE, de 2004 a 2007, desenvolvido como os demais a partir de análise de cenários, visou realinhar a Embrapa às novas prioridades decorrentes da troca de comando no governo federal. Já o V PDE, para o período de 2008 a 2023, chama a atenção para a determinação interna em valorização das atitudes cooperativas. Essa orientação é traduzida em diretrizes do V PDE, que melhor se prestam a revelar o modelo de gestão da empresa. Ressalta-se: 1) consolidar um modelo institucional e organizacional de gestão ágil e flexível, com autonomia para associações e parcerias; 2) ampliar a atuação em redes para aumentar a sinergia e a capacidade e velocidade da inovação e a transferência de tecnologia; e, ainda, outra diretriz que mereceu destaque nessa investigação: 3) fortalecer a comunicação institucional e mercadológica. Para assegurar a consecução de tais diretrizes, a Empresa optou por manter seu SGE como instrumento que disciplina a organização do trabalho e a gestão da carteira de projetos, bem como estabelece as instâncias decisórias na empresa.

Internamente, a ponta mais visível da gestão na Embrapa foi a instituição do painel de indicadores de desempenho, com metas e resultados atuais e passados da produção técnico-científica (artigos em anais, artigos em periódicos, capítulos de livro, orientação de teses, resumo em anais), produção de publicações técnicas (artigos na mídia, boletins, circulares técnicas), desenvolvimento de tecnologias, produtos e insumos (cultivares, estirpes, insumos, máquinas, metodologia científica), transferência de tecnologia e promoção da imagem (cursos, dias no campo, folders, estágios concedidos, palestras, vídeos, unidades demonstrativas e de observação). Comparando, haveria de se aceitar a aproximação (ou alinhamento) com os dados da Plataforma Lattes, do Conselho Nacional de Desenvolvimento Científico e Tecnológico (CNPq). Tal conjunto de indicadores pode e é utilizado para medir a produtividade das unidades e o desempenho dos próprios pesquisadores, exercendo papel não desprezível nas suas ações - à medida que isso reflete em sua carreira (Bernardi et al., 2008), em sua avaliação de desempenho (Ubeda e Santos, 2008) e em sua propensão a parcerias. ${ }^{3}$

\footnotetext{
${ }^{3}$ Souza e colaboradores (2007) testaram a relação entre parcerias e eficiência econômica de unidades da Embrapa e apontam para o efeito positivo das parcerias na medida de eficiência, o que,
} 
Ao longo dos anos e, aparentemente, em sintonia com as diretrizes estampadas nos PDEs, a Embrapa vem criando outros instrumentos gerenciais, como as políticas: de comunicação; de propriedade intelectual; de negócios tecnológicos; de pesquisa e desenvolvimento (Cardilho, 2007), e, mais tarde, a política de propriedade intelectual, que - dado o predomínio da Embrapa — teriam repercussão no campo de pesquisa agropecuário. Preocupações com marca, propaganda, contratos de exploração de material genético e exploração comercial de tecnologias geradas passaram a ser objeto de maior consideração, inibindo ou facilitando parcerias.

Adicionalmente, a empresa criou sistemas próprios, como: o "AinfoWeb", para disponibilização de informação contida em bases de dados (Zaninelli e Catarino, 2004), o "Ambitec", para avaliação de impacto ambiental de projetos em inovações da agropecuária mediante a ponderação de indicadores apropriados (Ávila et al., 2005; Bernardi et al., 2008; Bin, 2004; Monteiro e Rodrigues, 2006; Rodrigues, Campanhola e Kitamura, 2002) e a metodologia "Análise e melhoria de processos" para assessorar as unidades na reorganização do trabalho e na melhoria contínua dos processos (Amaral et al., 2008). No âmbito do SEP e mais tarde no SEG, a Embrapa desenvolveu, implantou, manteve ou alterou: o Sistema de Avaliação e Premiação por Resultados da Embrapa (com o seu Sistema de Avaliação das Unidades, em Guedes e Marinho, 2006); o Sistema de Planejamento, Acompanhamento e Avaliação de Resultados do Trabalho Individual; o Sistema de Avaliação da Produção de Pesquisa; o Sistema de Informação Gerencial e o Sistema do Plano Anual de Trabalho (Bin, 2004; Penteado, 2002).

Tomando Salles-Filho e colaboradores (2000), esse conjunto de ações na Embrapa apresentar-se-ia como coerente com processos de reorganização de outros institutos públicos de pesquisa na busca por legitimação: de ser reconhecido pelo Estado, pelas parceiras, pelos expoentes do setor produtivo e pela sociedade como organização de excelência em soluções técnicas, autossustentáveis e promotoras de desenvolvimento social, mediante a exploração racional de suas competências e divulgação de resultados alcançados, ligando-os à demanda social, com o fito de asseverar autonomia na organização da pesquisa, na gestão de recursos humanos, na captação e no uso de recursos e de ordem patrimonial - o que, em paralelo, estimula a busca por fontes complementares de recursos, mediante parcerias e comercialização de produtos

para esses autores, invalidaria as críticas de que o processo de avaliação prejudica a integração e a cooperação entre as unidades. 
das pesquisas, em um mercado de conhecimento onde digladiam os ofertantes, os tomadores e os financiadores de tecnologia; despontam possibilidades de arranjos público-privados e se valoriza a multidisciplinaridade e o trabalho em rede (Bin, 2004; Borges Filho, 2005).

Tais ações têm impacto, interno e externo. Enquanto o impacto externo é considerado na seção 4, o impacto interno, sobre os empregados, pode ser acompanhado no trabalho de Câmara (2007), que estudou prazer nas dimensões "liberdade" e "gratificação", juntamente com sofrimento, nas dimensões "desgaste" e "insegurança", implicados no contexto do trabalho na Embrapa. A pesquisadora detectou que as representações sobre a organização do trabalho - divisão do trabalho, normas, tempo e controle exigidos para o desempenho da tarefa - foram vistas interferindo "às vezes" ou "frequentemente" de modo negativo no contexto do trabalho, pois o ritmo de trabalho seria acelerado e a cobrança por resultados se faria presente. As vivências de sofrimento (fatores "insegurança" e "desgaste") foram encontradas prevalecentes sobre as vivências de prazer (fatores "gratificação" e "liberdade"), embora esses sentimentos de prazer se mostrassem também efetivamente presentes.

Já Mendes (2002) encontrou que a mudança da Embrapa para a estrutura de processo não teria trazido consigo, até então, os resultados esperados em termos de aumento de flexibilidade perceptível pelos empregados em função da resistência ao novo modelo.

Resistência e descrença se apresentaram também associadas à avaliação de desempenho e às implicações dessa diante do desenvolvimento de competências humanas (Ubeda e Santos, 2008). Por sua vez, Veiga (2007) relata resistências à implantação do MGE ante a designação coercitiva de responsáveis por objetivos, o atrelamento da premiação dos empregados à consecução desses objetivos e a insegurança devido à interdependência dos objetivos, para fora da autoridade do responsável. Essas resistências teriam persistido até a descontinuação do MGE, motivada pela troca de direção na empresa.

Para Brito e colaboradores (2002:13), a racionalidade burocrática dominante na Embrapa seria capaz de restringir a autonomia e a criatividade dos pesquisadores e impor uma disciplina orgânica que instrumentaliza a

orientação por resultados, determinando rigoroso controle, a mensuração e normatização de cada ato relativo ao trabalho dos pesquisadores... e provocou conflito entre a lógica de flexibilização e cooperação, condizentes com a organização multi e interdisciplinar, e a excessiva racionalização e controle sobre o processo de planejamento de projetos. 
Ressalvando a visão positiva do trabalho em equipe relacionado ao aprendizado e à rapidez em apresentar soluções tecnológicas, Brito e colaboradores (2002:14) também destacam a resistência e os limites percebidos pelos pesquisadores da Embrapa sobre o trabalho cooperado: individualismo, competição, dificuldades de relacionamento, falta de experiência, falha de comunicação entre áreas de conhecimento, conflitos de interesses na apropriação de resultados e paradoxo organizacional entre a orientação para o trabalho em equipe e a prática da avaliação baseada nos resultados do trabalho individual.

Ações e resistências conviveram no ambiente interno. Cabe agora uma reflexão tomando o campo científico da agropecuária, perquirido utilizando a metodologia descrita na próxima seção.

\section{Método da pesquisa}

Para investigar a produção científica em café e em soja, optou-se pela utilização da base de dados Scielo, através de busca compreendendo: "Artigo completo", "Soja" ou "Café", 4 " $2005,2006,2007,2008,2009$ ". A consulta foi feita entre $1^{\circ}$ e 5 de abril de 2009. Foram encontrados 450 artigos para a soja e 324 artigos para o café. Deste universo, foram excluídos os artigos que, a critério dos autores, fugiam totalmente do domínio da pesquisa agropecuária, como no caso de estudos históricos relativos à cafeicultura ou em pesquisas farmacêuticas de cafeína em guaraná. Dessa forma, reduziu-se a amostra para 443 artigos para a soja e 290 artigos para o café.

Foram identificadas as entidades coautoras dos $443+290$ trabalhos, atribuindo-lhe créditos proporcionais às participações (número de autores de cada entidade em um dado artigo). As participações e os créditos foram totalizados e calculou-se o Grau de Exogenia, GEXOG, medido pela razão entre o número de participações e o total de créditos aferido nos artigos, para cada entidade. Totalizou-se também a frequência em que as entidades apareciam como primeira autora (assim, tomada como entidade "líder"). Foi composto e apurado o índice denominado: Grau de Importância, GIMP, medido pela média aritmética da participação, crédito e primeira autoria, todos padronizados. Foram calculados dados estatísticos e construídos histogramas. Em paralelo, foram levantadas matri-

\footnotetext{
${ }^{4} \mathrm{E}$ outras derivadas como, por exemplo: cafeicultura, cafeicultor, cafezal etc., entre as oferecidas pelo Scielo.
} 
zes cruzadas entre as entidades, onde cada célula $\mathrm{a}_{\mathrm{ij}}, i \neq j$ continha o número de vezes que a entidade $i$ se coligou a $j$ (e vice-versa), descartando-se os trabalhos de apenas uma entidade. As matrizes permitiram a elaboração de sociogramas pelo emprego do software Pajek, que supriu diversos dados característicos das redes de coautorias, da pesquisa de soja e da pesquisa do café, como a densidade das redes e, para cada entidade participante, índices como: ${ }^{5}$ centralidade (closeness centrality e betweenness centrality), número de parcerias (all degree) e grau de redundância das ligações (aggregate constraint).

Para verificar como a Embrapa é retratada de forma científica, foram utilizadas a base de dados Scielo e a base de dados BDTD para recuperar artigos e monografias (dissertações e teses), respectivamente, publicados a partir de 2000 até a data da pesquisa (1ํ de abril de 2009), com expressão de busca: Embrapa e P\&D (Pesquisa e Desenvolvimento), no título ou em palavras-chave. Consultaram-se ainda diversos periódicos nacionais das áreas de Ciência \& Tecnologia, Administração e Sociologia, não inclusos no Scielo. Os autores encontrados tiveram a sua produção científica esquadrinhada empregando a Plataforma Lattes, o que implicou descoberta de outros artigos em periódicos e em anais. Ao final, foram obtidos 74 trabalhos científicos. Tais trabalhos foram estudados, catalogados e tabelados quanto a ano, entidade e área de conhecimento do primeiro autor, tipo (tese, dissertação, periódicos e anais), palavra-chave, temática e metodologia empregada. Serviram também como fonte de dados secundários utilizados na investigação, que também lançou mão de 1) material institucional disponíveis no site da Embrapa e do próprio site da Embrapa, em 1ㅇ de abril de 2009 e 2) dados da Coordenação de Aperfeiçoamento de Pessoal de Nível Superior (Capes), do CNPq e do IBGE. Por fim, na fase mais qualitativa, foi utilizada a análise de conteúdo em documentos e em transcrição de entrevistas realizadas por Araújo (2008) e disponibilizada para essa investigação.

\section{Resultados e discussão}

\subsection{Pesquisa agropecuária no Brasil}

No Brasil, e de acordo com as últimas atualizações disponíveis (Brasil, 2007), tem-se que o dispêndio em P\&D atingiu 20,5 bilhões de dólares, equivalente a

\footnotetext{
${ }^{5}$ Para definição desses termos, consultar Nooy, Mrvar e Batagelj (2006).
} 
1,11\% do PIB, dos quais os dispêndios públicos responderam pela parcela de $0,59 \%$ do PIB $(0,41 \%$ federal e $0,19 \%$ estadual, metade de ambos utilizada no financiamento da pós-graduação) e os dispêndios empresariais responderam pelos restantes 0,52\% do PIB.

Em 2007, o investimento em pesquisa na agricultura foi de 1,5 bilhão anuais (próximo a 10\% do total). A Embrapa se apropriou de aproximadamente dois terços desse total, apenas em transferência direta do Tesouro, sobre a qual deve ser ainda acrescida uma parcela obtida de outras fontes. Nesse ano, o orçamento da Embrapa foi próximo a 1,2 bilhão, três quartos dos quais destinados à folha de pagamentos, encargos e benefícios (Embrapa, 2009b). Mas, quando se analisa a distribuição de recursos via editais competitivos, a participação da Embrapa é substancialmente menor. A tabela 1 apresenta a divisão do montante de 58 milhões de reais entre algumas entidades, relativos a editais promovidos pelo CNPq para apoio a projetos de pesquisa, em 2008, na grande área de ciências agrárias.

Tabela 1

\section{Captação de recursos em edital do CNPq}

\begin{tabular}{|lcccc|}
\hline ENTIDADE & Projetos $(\mathrm{P})$ & Total $(\mathrm{R} \$)$ & $\mathrm{R} \$ / \mathrm{P}$ & \% Total \\
\hline Embrapa & 253 & 7.328 .259 & 28.965 & $13 \%$ \\
UFV & 128 & 5.190 .158 & 40.548 & $9 \%$ \\
USP (incluindo Esalq) & 121 & 3.627 .207 & 29.977 & $6 \%$ \\
Ufla & 78 & 1.760 .029 & 22.564 & $3 \%$ \\
Unesp & 80 & 1.404 .388 & 17.555 & $2 \%$ \\
Outras & 1.323 & 38.477 .256 & 29.083 & $67 \%$ \\
\hline Total Geral & 1.983 & 57.787 .299 & 29.141 & $100 \%$ \\
\hline
\end{tabular}

Fonte: Conselho Nacional de Desenvolvimento Científico e Tecnológico (CNPq) (2009). Tabulação própria.

A Embrapa foi a entidade mais bem aquinhoada, mas não obteve mais que $13 \%$ do total. UFV, USP, Ufla e Unesp, em conjunto, conseguiram $21 \%$. Não haveria indicação de uma maior eficiência da Embrapa diante das entidades de referência na captação de recursos em editais competitivos, considerando os respectivos quadros de pesquisadores.

Enquanto o quadro de pesquisadores da Embrapa é conhecido - em torno de 2.200 (Embrapa, 2009b) —, é necessário fazer algumas inferências para estimar a quantidade de pesquisadores que voltam seus esforços para o setor agropecuário. De acordo com o último censo do CNPq (2009), em 
2006 o Brasil contava com 8.128 pesquisadores doutores na grande área de ciências agrárias, cadastrados na Plataforma Lattes. Quando se acrescentam os não doutores, o número sobe para 10.840 (o que corresponderia a $12 \%$ dos pesquisadores brasileiros), distribuídos em 167 entidades, 2.041 grupos de pesquisa e 9.917 linhas de pesquisa. Tomando dados de final de 2007, havia ainda um contingente de 13.208 estudantes, $41 \%$ no doutorado, distribuídos em 262 programas de pós-graduação, capazes de converter pesquisas em dissertações e teses. Sobre esse volume, devem ser acrescidos ainda os pesquisadores que não se interessaram por se inscrever na Plataforma Lattes, mormente aqueles da iniciativa privada.

Segundo a Coordenação de Aperfeiçoamento de Pessoal de Nível Superior (Capes) (2009), tomando por base o ano de 2007 e considerando apenas os docentes de cursos de pós-graduação na grande área de ciências agrárias, tem-se que: a Unesp, com 413; a UFV, com 284; a Ufla, com 189 e a Esalq, ${ }^{6}$ com 161 pesquisadores docentes permanentes, são as universidades com maior contingente - um total de 1.047 (99,7\% deles doutores) pesquisadores altamente qualificados, que contam com uma força auxiliar de estimados 3.800 pós-graduandos (3,7 discentes/docentes). Seria razoável supor que, em conjunto, tais entidades teriam uma força de pesquisa equivalente à da Embrapa. Sobrariam, ainda, 593 pesquisadores efetivos nas Oepas (Centro de Gestão de Estudos Estratégicos, 2006:65), os pesquisadores das demais entidades de ensino e seus alunos e, por fim, os pesquisadores da iniciativa privada.

Ao se fazer os 3,7 discentes iguais a um pesquisador docente permanente e um total de 3.656 pesquisadores docentes permanentes, e acrescendo os não doutores, já se contabilizariam algo próximo a 15.000 pesquisadores equivalentes, mesmo não considerando aqueles não encontrados na Plataforma Lattes. Daí parecer de pouco risco afirmar que o efetivo da Embrapa é inferior a $15 \%$ do total de pesquisadores brasileiros na grande área de ciências agrárias.

Por outro lado e de acordo com a Capes (2009), em março de 2008, a Embrapa contava com 146,7 bolsas de produtividade do CNPq em todas as áreas (126,8 bolsas de produtividade na grande área de ciências agrárias). Considerando um quadro de 1.683 doutores (Embrapa, 2009b), tem-se menos de 0,1 bolsa por pesquisador doutor. Pode-se comparar essa relação com

\footnotetext{
${ }^{6}$ Quando se acrescentam as outras unidades da USP ao efetivo da Esalq, o número de pesquisadores docentes permanentes na grande área de ciências agrárias chega a 327 na USP (Coordenação..., 2009).
} 
aquela tomando como referência os professores doutores da Unesp, UFV, USP e Ufla listados na grande área de ciências agrárias, como apresentado na tabela $2 .^{7}$ Em conjunto, nessas universidades e na área considerada, a proporção varia entre 0,37 e 0,57 bolsa de produtividade por pesquisador doutor. Por esses dados não haveria uma diferença favorável à Embrapa quanto a esse indicador de produtividade.

Tabela 2

Bolsas de produtividade Capes e pessoal, em 2007/08, ciências agrárias, exceto Embrapa (total)

\begin{tabular}{|c|c|c|c|c|c|c|}
\hline \multirow[b]{2}{*}{ ENTIDADE } & \multirow{2}{*}{$\begin{array}{c}\text { Dr. } \\
\text { docentes }\end{array}$} & \multirow{2}{*}{$\begin{array}{c}\text { Dr. } \\
\text { pesquisadores }\end{array}$} & \multirow{2}{*}{$\begin{array}{c}\text { Bolsas de } \\
\text { produtividade }\end{array}$} & \multirow{2}{*}{$\begin{array}{c}\text { Bolsas por } \\
\text { doutor }\end{array}$} & \multicolumn{2}{|c|}{ Pós-graduandos } \\
\hline & & & & & Doutorado & Mestrado \\
\hline Embrapa & - & 1683 & 146,7 & 0,09 & - & - \\
\hline UFV & 284 & - & 149,8 & 0,53 & 713 & 701 \\
\hline USP & 327 & - & 174,9 & 0,53 & 711 & 721 \\
\hline Ufla & 189 & - & 106,9 & 0,57 & 411 & 498 \\
\hline Unesp & 413 & - & 153,7 & 0,37 & 917 & 828 \\
\hline Outras & 2435 & - & 685,6 & 0,28 & 2.627 & 5081 \\
\hline Total Geral & 3648 & - & 1397,7 & 0,38 & 5.379 & 7829 \\
\hline
\end{tabular}

Fonte: Coordenação..., 2009, Conselho..., 2009 e Embrapa, 2009c. Tabulação própria.

Falhando em encontrar evidências significativas entre a produtividade dos pesquisadores das entidades consideradas (pelo menos no indicador selecionado), que também se assemelham na competência de amealhar recursos em editais competitivos, a contribuição da Embrapa no esforço científico deveria se limitar a ser proporcional a sua força de trabalho (15\% dos pesquisadores), hipótese investigada na seção seguinte.

\footnotetext{
${ }^{7}$ Não foi encontrada disponível (mesmo mediante solicitação) a distribuição dos pesquisadores da Embrapa por área de conhecimento. A tabela 2 sofre desse inconveniente: os dados da Embrapa são relativos a todas as áreas, enquanto para as demais entidades foi possível apresentar os dados relativos à grande área de ciências agrárias - foco do estudo.
} 


\subsection{A Embrapa na pesquisa de soja e do café}

Há uma razoável ligação entre a soja e a Embrapa. ${ }^{8}$ Essa ligação é relativamente desproporcional quando se toma em consideração o grau de importância da Embrapa na pesquisa de soja, apresentado na tabela 3, obtido da amostra descrita na seção 3. Como esperado, a Embrapa foi encontrada ocupando a primeira posição, mas não está distante da Unesp, UFV e Esaq + USP (outras) no que diz respeito ao indicador "Grau de importância".

No entanto, a amostra fornece dois dados interessantes: a Embrapa é a entidade de mais alta exogenia - calculada como indicado na seção 3 - entre as 10 entidades destacadas (do total de 143 entidades). Isso implica dizer que, comparada com as outras nove entidades mais importantes na pesquisa de soja, a Embrapa é aquela que mais procura parcerias, mesmo que isso não a leve a ser a primeira autora do trabalho. Ela distribui sua participação em maior número de pesquisas, conferindo-se um maior grau de "alavancagem". Isso aparece também nos sociogramas da rede de coautoria ${ }^{9}$ e na última coluna da tabela 3, que indica a centralidade (closeness centrality, software Pajek) das entidades. A Embrapa não seria a mais central apenas por ser mais importante, mas também por confiar mais em parcerias.

Tabela 3

Produção científica em soja

\begin{tabular}{|c|c|c|c|c|c|c|}
\hline \multirow[b]{2}{*}{ ENTIDADE } & \multicolumn{3}{|c|}{ Artigos } & \multirow{2}{*}{$\begin{array}{c}\text { Grau de } \\
\text { Importância }\end{array}$} & \multirow{2}{*}{$\begin{array}{l}\text { Grau de } \\
\text { Exogenia }\end{array}$} & \multirow{2}{*}{$\begin{array}{c}\text { Grau de } \\
\text { Centralidade }\end{array}$} \\
\hline & Participação & Líder & Créditos & & & \\
\hline Embrapa & 105 & 48 & 47,01 & 0,11 & 2,23 & 0,56 \\
\hline Unesp & 73 & 43 & 50,94 & 0,10 & 1,43 & 0,48 \\
\hline UFV & 55 & 32 & 40,80 & 0,08 & 1,35 & 0,45 \\
\hline Esalq & 50 & 29 & 27,41 & 0,06 & 1,82 & 0,46 \\
\hline UFSM & 37 & 27 & 28,14 & 0,06 & 1,31 & 0,45 \\
\hline Ufla & 34 & 25 & 27,82 & 0,05 & 1,22 & 0,40 \\
\hline UFRGS & 29 & 14 & 17,09 & 0,04 & 1,70 & 0,42 \\
\hline
\end{tabular}

Continua

\footnotetext{
${ }^{8}$ Consultando o sistema de busca Google Acadêmico, na internet, no dia 18 de abril de 2009, foram encontradas 279 mil entradas para "soja" e 21,2 mil entradas para "soja" + "Embrapa", portanto, $8 \%$ do total. Essa associação é quatro vezes maior em média quando se liga "soja" à "Unesp", ou "UFV", ou "Esalq", ou "Ufla".

${ }^{9}$ Os sociogramas não são apresentados por restrições gráficas. Eles estão disponíveis mediante solicitação.
} 


\begin{tabular}{|c|c|c|c|c|c|c|}
\hline \multirow[b]{2}{*}{ ENTIDADE } & \multicolumn{3}{|c|}{ Artigos } & \multirow{2}{*}{$\begin{array}{c}\text { Grau de } \\
\text { Importância }\end{array}$} & \multirow{2}{*}{$\begin{array}{c}\text { Grau de } \\
\text { Exogenia }\end{array}$} & \multirow{2}{*}{$\begin{array}{c}\text { Grau de } \\
\text { Centralidade }\end{array}$} \\
\hline & Participação & Líder & Créditos & & & \\
\hline UEL & 29 & 16 & 13,21 & 0,03 & 2,19 & 0,42 \\
\hline UEM & 26 & 18 & 20,21 & 0,04 & 1,29 & 0,43 \\
\hline USP (outras) & 18 & 10 & 9,76 & 0,02 & 1,84 & 0,40 \\
\hline
\end{tabular}

Fonte: Dados próprios definidos e obtidos como indicado na seção 3.

Um domínio absoluto da Embrapa na pesquisa da soja é passível de contestação até mesmo histórica, como depreendido do depoimento do pesquisador A02, capaz de discorrer longamente sobre a conquista do cerrado brasileiro, sem ao menos citar a Embrapa, que afinal, na época, estava ainda em criação.

Pesquisador A02: O programa de soja no Brasil, ela... ela nasceu aqui em Minas Gerais, nasceu aqui... Essa coisa toda começou na Epamig em 1972, certo?! Nós estávamos aqui no Brasil [...] à beira de um colapso de abastecimento. Não havia ah... mais fronteira pra produção de alimentos no país. E o país crescia... fantasticamente em termos de população. Então, ou se... ou se conquistava o cerrado ou então nós íamos ter uma... uma... e ninguém acreditava no cerrado. Ninguém acreditava no cerrado, então foi um avanço muito grande... a soja nasceu ali... com a pesquisa de... do Pipaemg ali na... com o Padap — Programa de Assentamento Dirigido no Alto do Paraíba, lá na região de São Gotardo: um programa de assentamento feito pelo estado de Minas Gerais e pelo BDMG, se eu não me engano. Mas capitaneado pela secretaria da agricultura e eu me lembro... Com as pesquisas do Pipaemg, UFV, Ufla, Epamig etc. e tal [...] Foi um programa muito bem estruturado, o programa do Padap, que depois virou Polocentro (Programa de Desenvolvimento do Cerrado), tá?! A nível nacional e de lá então, a soja ganhou fóruns nacionais. $\mathrm{E}$ de lá ela irradiou pra... pra Mato Grosso, Goiás etc. e tal... e subiu... e subiu o Brasil. E de lá se deu muito programa de sucesso e a Epamig teve muito sucesso, fez isso com muita competência. Não teve a competência bastante pra mostrar pro Estado e pra sociedade brasileira a importância dela (Araújo, 2008)

De'Carli corrobora A02 na medida em que, para De'Carli (2005:74),

a expansão da soja no Brasil aconteceu nos anos 70, com o interesse crescente da indústria de óleo e a demanda do mercado internacional por uma fonte 
proteica em substituição da farinha de peixe, cuja produção estava em declínio; além do desenvolvimento das primeiras cultivares comerciais.

Mas o tema é controverso, na medida em que autores apontam um papel crucial cumprido pela Embrapa para a implantação de uma lógica de ocupação intensiva do cerrado, imputando à empresa o desenvolvimento de variedades vegetais adaptadas aos sistemas agrícolas da região (Pietrafesa e Sauer, 1997).

Cabe ressaltar outra forma de inferir a importância da Embrapa na pesquisa de soja, que diz respeito ao volume de sementes comercializadas de cultivares detidas pelas entidades. Se essa for considerada uma proxy válida de contribuição à pesquisa, a Embrapa se destaca das demais (Carvalho, Salles-Filho e Paulino, 2007; Fuck, 2005), tendo papel importante na concorrência do mercado de sementes, ${ }^{10}$ evitando que esse mercado seja dominado por grandes corporações multinacionais em detrimento das empresas sementeiras e produtores rurais nacionais (Carvalho, Salles-Filho e Paulino, 2007; Fuck et al., 2007; De'Carli, 2005). O problema estaria em que assim se limita o campo da pesquisa agropecuária às áreas da genética e do melhoramento.

Uma explicação possível para o desequilíbrio entre produção acadêmica ante direitos de cultivares vai além do gradiente de competência técnica, estando relacionado com a forma de apropriação dos resultados decorrentes da inovação. Enquanto a Embrapa, como empresa, retém e aplica a receita advinda de sua parcela de contribuição sobre as sementes de soja comercializadas, as universidades não possuiriam essa motivação, como visto no depoimento de A30.

Pesquisador A30: Do mesmo jeito fizemos equipes fortes pra soja. Já saiu daqui mais de cinquenta variedades de soja. Onde é que tem colheitadeira de soja? Nenhuma. Nenhuma - num tem aqui. E, no entanto, se você for pegar hoje royalties de pesquisa de soja, a universidade num recebe um centavo do governo federal. Se fosse pegar, né? Se a lei valesse alguma coisa... (Araújo, 2008)

Voltando-se agora para a pesquisa do café, é apresentada a tabela 4.

\footnotetext{
${ }^{10}$ De acordo com a Embrapa, apud De'Carli (2005:85), em 2004, 42\% da área plantada com soja no Brasil utilizava material da Embrapa, que detinha na época $31 \%$ das cultivares de soja protegidas.
} 
Tabela 4

Produção científica em café

\begin{tabular}{|lcccccc|}
\hline Entidade & Participação & $\begin{array}{c}\text { Artigos } \\
\text { Líder }\end{array}$ & Créditos & $\begin{array}{c}\text { Grau de } \\
\text { Importância }\end{array}$ & $\begin{array}{c}\text { Grau de } \\
\text { Exogenia }\end{array}$ & $\begin{array}{c}\text { Grau de } \\
\text { Centralidade }\end{array}$ \\
\hline Ufla & 111 & 57 & 75,01 & 0,22 & 1,48 & 0,60 \\
UFV & 70 & 41 & 47,41 & 0,14 & 1,48 & 0,48 \\
IAC & 35 & 24 & 22,69 & 0,07 & 1,54 & 0,46 \\
Embrapa & 41 & 19 & 16,60 & 0,06 & 2,47 & 0,50 \\
Epamig & 40 & 16 & 13,83 & 0,06 & 2,89 & 0,48 \\
Unesp & 18 & 12 & 10,28 & 0,04 & 1,75 & 0,47 \\
Esalq & 19 & 11 & 8,70 & 0,03 & 2,18 & 0,49 \\
Uenf & 9 & 9 & 8,00 & 0,02 & 1,13 & 0,32 \\
Unicamp & 21 & 3 & 6,85 & 0,02 & 3,07 & 0,49 \\
Ufes & 12 & 8 & 5,30 & 0,02 & 2,26 & 0,46 \\
\hline
\end{tabular}

Fonte: Dados próprios definidos e obtidos como indicado na seção 3.

De acordo com a tabela 4, mesmo mantendo um alto grau de exogenia, o grau de importância da Embrapa - calculado como indicado na seção 3 - é significativamente menor na amostra que explora a pesquisa de café $(0,06$ para o café, diante de 0,11 na soja): a Embrapa atingiu apenas a quarta posição, empatada com a Epamig e atrás da Ufla, UFV e IAC.

Tais resultados tendem a confirmar aqueles de Araújo (2008), que utilizou a mesma metodologia, mas aplicou-a em trabalhos publicados nos Simpósios de Pesquisa de Café no Brasil, coordenados pelo Consórcio Brasileiro de Pesquisa e Desenvolvimento do Café (CBPDC). Avalia-se que essa concordância implica uma indicação de confiabilidade do método empregado.

Diante das amostras consideradas, a rede da soja apresentou 143 vértices para 443 trabalhos com 300 ligações diáticas (pares) distintas em 487 ligações no total. Em média, cada trabalho teve 1,8 entidade envolvida (43\% dos trabalhos foram exclusivos de uma entidade). Na rede, cada vértice teve, em média, 4,26 parceiros (máximo de 55, caso da Embrapa). As 10 entidades mais importantes acumularam $64 \%$ dos créditos.

A rede de café, composta por 87 entidades em 290 trabalhos com 179 ligações diáticas distintas em um total de 360 ligações, foi encontrada com densidade (média de 4,11 parceiros por entidade, máximo de 42 parceiros, 
caso da Ufla) e propensão a parcerias semelhantes (1,9 entidade envolvida em média por trabalho; $43 \%$ dos trabalhos exclusivos de uma entidade). Contudo, quando comparada à soja, a rede do café é mais concentrada: das 87 entidades (para 290 trabalhos, portanto, proporção de 3,3 trabalhos por entidade), as 10 mais importantes responderam por $74 \%$ dos trabalhos. Cabe, por fim, ainda observar que os Graus de Exogenia dessas entidades mais importantes tendem a ser maiores no café do que na soja.

A pesquisa em café é diferente da pesquisa em soja. Seja por condicionantes históricos ou até mesmo devido a fatores naturais, tal como discorrido pelo pesquisador A15: “(...) Trabalhar com o café é diferente de você trabalhar com milho, com soja - que você planta hoje, daqui a três meses, quatro meses, você colhe, cê... realiza a pesquisa. Café cê tem que preparar a lavoura né, éh... formar a lavoura, conduzir tudo. É um negócio de longo prazo" (Araújo, 2008). Ainda, o café conta com um consórcio de pesquisa oficial, atuando há mais de 10 anos. Daí ser significativo apontar as semelhanças estruturais encontradas entre as respectivas redes de pesquisadores.

\subsection{Marketing jornalístico da Embrapa}

Desde 1995, a Embrapa atua ativamente na área de comunicação, considerando-a estratégica, tendo ensejado a elaboração da sua Política de Comunicação Empresarial. Em 2002, tal política foi revisada, considerando que a marca, a imagem e a reputação seriam fundamentais para a legitimidade e liderança da empresa. A gestão da imagem da Embrapa seria de responsabilidade de todos os seus empregados, em cada contato com o público de interesse e com a sociedade, reconhecendo a necessidade de tornar visíveis suas pesquisas, seus produtos e seus serviços. Entre outros propósitos, visando sua própria sustentabilidade institucional, a Embrapa espera que sua política de comunicação contribua:

[...] para criar, ampliar ou reforçar, junto aos diversos públicos de interesse da Empresa, o conceito de competência institucional da Embrapa, definido pela confiabilidade de sua tecnologia, pela qualificação de seu corpo técnico e pela reconhecida capacidade de resolver problemas sociais, ambientais e de contribuir para a melhoria da qualidade de vida dos cidadãos (Embrapa, 2002:35).

Para tanto, a empresa admite lançar mão de assessoria de imprensa, relações públicas, promoção, publicidade e propaganda, jornalismo empresarial, 
programas de identidade visual e de comunicação interna, avaliação institucional junto aos vários públicos de interesse, pesquisas de opinião - internas e externas - e auditoria de imagem na mídia (Embrapa, 2002:41).

A Embrapa vem tendo sucesso na implementação de sua política de comunicação. Penteado e colaboradores (2007) colecionaram nada menos que 17.000 registros jornalísticos relacionados à Embrapa nos anos de $2003 \mathrm{e}$ $2004,{ }^{11}$ mais da metade delas por iniciativa da empresa (Monteiro, 2005). Não se procura apenas divulgar as realizações da Embrapa, mas torná-las crível pela imprensa e ainda pautar/enquadrar o noticiário da forma mais conveniente (Cardilho, 2007; Silva et al., 2007).

Em estrita correspondência com sua política, os releases da Embrapa mesclam os discursos publicitários, de marketing e tecnológico em um composto que pretende justificar a importância de se investir na empresa (Silva et al., 2007), ainda que embalados por uma justificativa de accountability: a responsabilidade de responder pelos recursos empenhados (Monteiro, 2005). A notícia científica seria só mais uma das tantas ferramentas de marketing, mais uma peça de promoção, eventualmente distorcida (Silva et al., 2007:5758). É desse prisma que se pode entender a divulgação do Balanço Social da Embrapa (Embrapa, 2009b). Mais do que comprovar a eficiência na utilização de recursos (14 vezes por real investido em 2008), configurar-se-ia em uma distinção por ser a única entidade pública de pesquisa a fazê-lo.

Utilizando-se das lentes de Bourdieu (2004), enquanto tais práticas são amplamente aceitáveis no ambiente de negócios, elas trazem à arena elementos que são externos ao campo científico, onde a reputação (de pesquisadores e das entidades) deveria ser efeito da competência técnica. Ao fazê-lo, incorrer-se-ia no risco de subordinar crescentemente a pesquisa a pressões externas, abdicando-se de parte da autonomia que deveria gozar o campo, desequilibrando-se a ciência para o lado da ciência escrava, sujeita a todas as pressões político-econômicas (Bourdieu, 2004:21).

O interessante é que isso aparentemente não provoca uma reação por parte dos pesquisadores de outras entidades, que competem por recurso no mesmo campo. Pelo contrário, na pesquisa de Araújo (2008), mesmo tendo o pesquisador entrevistado gozado de amplas oportunidades para discorrer a respeito, apenas 2 em 39 deles se manifestaram a respeito do marketing da Embrapa, e isso em tom de aceitação e até de admiração:

${ }^{11}$ Notícias em jornais como o Estado de S. Paulo; revistas como Globo Rural e Balde Branco. 
Pesquisador A09: (O marketing da Embrapa) é forte. Ela tem tudo divulgado, tem tudo. Tem tudo. Aqui (na universidade) num tem divulgado, num tem nada. Eles (a Embrapa) fazem um pouco de marketing, eles são agressivos.

Pesquisador A31: [...] de todas as formas, a Embrapa é muito forte na área de marketing. Ela é realmente excepcional, né? Até acho que nós até deveríamos aprender um pouquinho... Copiar deles... Deveríamos ser mais... agressivos, no marketing... Por exemplo, quando a Embrapa fala que... ela abriu o cerrado com a sua soja, isso incomoda... a UFV por exemplo, que participou ativamente, antes da Embrapa Soja existir. Antes deles virem, ela (a UFV) já tava lá com soja. A gente sabe que ela (a Embrapa) é muito grande, então já num depende da opinião de uma pessoa. Às vezes a gente conversa com um técnico (pesquisador) da Embrapa, mas ele é tão impotente também dentro de uma estrutura tão grande. O técnico já num tem mais poder pra conter as ações de marketing da Embrapa. Ela tem outra equipe especializada, em marketing, que faz isso... Às vezes a gente reclama com os colegas, né? "Pô, cês exageram..." "Ahh, ali num tem jeito não." Assim que eles respondem. Num tem jeito mesmo, realmente. Eles têm um departamento de marketing. Nem agrônomo, num é.

Uma leitura possível é que entre colegas cientistas vale o mérito acadêmico, mas a Embrapa lança mão de recursos extracampo para construir uma imagem que lhe seja favorável, mesmo se apropriando de realizações de outras entidades. No que tange à soja, o depoimento de A31 encontra comprovação em A02, que indicou trabalhos científicos de entidades mineiras, iniciados mesmo antes da criação da Embrapa, como marco da conquista do cerrado.

\subsection{Embrapa como objeto de pesquisa}

A par e passo com o diferencial em capital humano, a comunicação destaca a eficiência do modelo de gestão Embrapa, capaz de maximizar seus recursos em benefício da sociedade. Tal modelo tem atraído a atenção de pesquisadores que convertem a Embrapa de agente em objeto de pesquisa. Enquanto se espera comportamento finalístico na seara da comunicação institucional, o desavisado pode ainda crer na neutralidade científica: o pesquisador estaria escudado de interferências de outra ordem que aquela do rigor científico, quando se analisa a Embrapa. Essa crença positivista não teria resistido ao teste descrito e relatado a seguir.

Dos 74 trabalhos que compuseram a amostra de utilização da Embrapa como objeto de pesquisa, 33 foram divulgados em periódicos e 21 em anais de 
encontros e simpósios científicos. Os demais são dissertações (17), teses (2) e um relatório. Ao classificar os interesses dos primeiros autores desses trabalhos em função de sua área de competência declarada nos respectivos currículos na Plataforma Lattes, verifica-se uma dispersão, destacando administração (14), economia (14), ciência da informação e computação (10), agronomia (9) e comunicação (7) - o que diz alguma coisa sobre a temática tratada, que foi revelada mediante cruzamento das palavras-chave com o tema e problema da pesquisa.

Dessa forma, as pesquisas foram agrupadas naquelas que: a) utilizaram a Embrapa como campo de teste de algumas teorias e ferramentas científicas; b) se propuseram a estudar as práticas gerenciais e ferramentas da Embrapa, alocadas em subgrupos: b1) entre essas práticas, aquelas voltadas para a gestão da informação e do conhecimento; b2) aquelas voltadas para a gestão da comunicação; b3) aquelas voltadas para métodos empregados na avaliação de impacto de tecnologias; b4) aquelas voltadas para a organização interna do trabalho; e b5) aquelas que se voltaram para a questão da estratégia na Embrapa. Por fim, o grupo c) de pesquisas que se propuseram a investigar alguma implicação da Embrapa no campo agropecuário da ciência \& tecnologia. Apenas sete dos 74 trabalhos examinados foram encaixadas no grupo c; a maior fração dos restantes no âmbito do grupo b (62, portanto, $83 \%$ dos trabalhos). ${ }^{12}$

Do conjunto considerado, os primeiros autores que assinam os trabalhos pertenciam, quando de sua publicação, à Embrapa ( 55 dos 74 trabalhos, portanto, 74\% deles), Unicamp (seis trabalhos), Ufla (dois trabalhos) e outras 10 entidades (um trabalho cada). No que tange à metodologia utilizada, apenas 25 se basearam em dados empíricos próprios (questionários e/ou entrevistas). Os demais trabalharam com dados secundários, mormente publicações institucionais da Embrapa ou com referências a outros autores (pesquisas bibliográficas). Quase a totalidade se encaixou (ou seria assim classificado) como estudo de caso e descritivo.

Quando se consideram as exigências de rigor metodológico (entendido como a explicitação e o alinhamento dos polos ontológicos, epistemológicos, teóricos, morfológicos e técnicos), a regra foi ignorá-lo. Uma vez não indicada de forma explícita, a classificação paradigmática requer certa dose de arbitrariedade, mas seria seguro afirmar que a maioria qualificada dos trabalhos

\footnotetext{
${ }^{12}$ Citam-se como elementos típicos: do grupo a — Souza e Ávila (2000); do subgrupo b1 — Pierozzi Júnior e colaboradores (2003); do subgrupo b2 - Monteiro (2005); do subgrupo b3 — Rodrigues, Campanhola e Kitamura (2002); do subgrupo b4 — Ubeda e Santos (2008); do subgrupo b5 — Galas e Forte (2004); do grupo c — Fuck e Bonacelli (2007).
} 
se veria encaixada no paradigma positivista, com poucas exceções, como os trabalhos de Brito e colaboradores (2002) e Silva (2007).

Per se, o fato de a maioria dos trabalhos ser de pesquisadores da Embrapa não traria problemas e seria o esperado, pois, afinal, eles possuem maior acesso ao objeto de pesquisa. Contudo, ao desconsiderar questões quanto a sua neutralidade científica (tão mais necessária quando mais imerso no objeto de estudo), dispensar dados empíricos próprios, não se ocupar adequadamente de demonstrar o rigor metodológico e frequentemente adotar o viés positivista (em detrimento de outras possibilidades), em sua maioria, de dois a cada três, os trabalhos podem ser tidos como relatos da experiência da Embrapa, onde o que está implícito é a viabilidade de adotá-la como modelo bem-sucedido, merecedor de atenção especial. A citação a seguir exemplifica o caráter propositivo que permeia uma fração significativa da amostra de trabalhos acadêmicos estudada:

Entretanto, cabe destacar que, apesar das evidências de impactos positivos e dos altos retornos dos recursos nela investidos, nos últimos dez anos, observase um decréscimo no montante de recursos alocados na Empresa. Portanto, é necessário recolocar o volume de investimentos na Embrapa, em níveis mais compatíveis com as suas reais e crescentes necessidades, para que ela possa, no futuro, manter ou até mesmo ampliar o seu papel no desenvolvimento brasileiro (Ávila et al., 2005:101).

Daí não parecer incorreto afirmar que o marketing jornalístico encontra reforço no que poderia ser tido como marketing científico, na construção da imagem da Embrapa como modelo bem-sucedido, o que tem implicações na ordem de sua legitimação, pelo menos junto aos cientistas, público que tem acesso a tais trabalhos.

A combinação de marketing jornalístico e científico produz resultados. Tais esforços induzem a uma percepção na qual a "Embrapa é vista por parte dos governantes (estaduais) como capaz de substituir total e convenientemente o esforço estadual de pesquisa agropecuária" (Centro de Gestão de Estudos Estratégicos, 2006:114) — assunto que é explorado a seguir.

\subsection{Coordenação do Sistema Nacional de Pesquisa Agropecuária (SNPA)}

A Embrapa recebeu no ato de sua criação a responsabilidade de coordenar o SNPA. Para tanto, a Embrapa poderia "conceder apoio financeiro para ativi- 
dades de pesquisa de seu interesse, a serem executadas por outras entidades, repassando os recursos financeiros, mediante convênio ou contrato de projetos de pesquisa específico" - conquanto que, acumulativamente, as entidades candidatas ao convênio adotem da Embrapa suas diretrizes organizacionais, sua metodologia de trabalho e de avaliação, e ainda estejam em consonância com os sistemas de programação e de controle técnico e financeiro fixados pela Embrapa. Ademais, mesmo ao delegar algumas de suas pesquisas, a Embrapa se reserva a exercer "sobre essas atividades ação de caráter normativo, programático, de coordenação e de acompanhamento e avaliação de resultados, na conformidade do que for estabelecido em convênio, contrato ou ajuste" (Brasil, 1997).

De tal forma que a Embrapa estaria juridicamente equipada para exercer a coordenação do SNPA, em um arranjo inicial onde as universidades fariam a pesquisa básica, a Embrapa a pesquisa aplicada, as Oepas, articuladas com as unidades da Embrapa, se responsabilizariam tanto pelas pesquisas de interesse local quanto pela adequação dos resultados das pesquisas da Embrapa às condições do lugar (Fuck, 2005), a Empresa Brasileira de Assistência Técnica e Extensão Rural (Embrater) e as Empresas de Assistência Técnica e Extensão Rural estaduais (Ematers) se encarregariam da difusão e transferência da tecnologia aos produtores. No arranjo, as entidades trabalhariam de forma articulada e complementar, de modo a facilitar a obtenção de economias de escala e de escopo na execução de projetos - e a Embrapa identificaria as demandas, faria o planejamento e propiciaria apoio técnico e financeiro (Fuck, 2005; Fuck e Bonacelli, 2007). Tal arranjo configurar-se-ia em um sistema, caracterizado pela diferenciação, a especialização e a integração (Morgan, 2007:50).

Mas essa disposição foi gradativamente esvaziada, até mesmo pela extinção da Embrater, em 1990, e por uma dinâmica explorada por Borges Filho (2005). Tal divisão do trabalho, em toda a sua racionalidade, não restou real. Nas condições atuais, a Embrapa verticalizou sua ação: faz a prospecção, define as prioridades (Joseph, 2001), faz a captação de recursos, emite os editais, monta as parcerias (onde, por efeito de seus editais, é a entidade líder - exceto na pesquisa do café), escolhe os projetos, realiza a pesquisa, valida, divulga, difunde e faz a transferência (Vieira, Oliveira e Domit, 2004), e analisa os impactos da tecnologia gerada (Bernardi et al., 2008; Bin, 2004; Monteiro e Rodrigues, 2006; Rodrigues, Campanhola e Kitamura, 2002) - e se vê satisfeita com os resultados, tanto de suas pesquisas quanto do status quo do campo da pesquisa agropecuária - como evidenciado em seus balanços sociais, onde a Embrapa (não o SNPA, cujo balanço a Embrapa não se propõe 
a fazer) daria um retorno de 14 vezes por real investido, independentemente das demais entidades do SNPA. Seria no mínimo questionável conferir a denominação "Sistema" a um arranjo em que uma das partes não esteja em relação de interdependência junto às demais e possa produzir resultados tão expressivos e dissociados dos demais componentes. ${ }^{13}$ Vai-se além de Fuck e Bonacelli (2007:95), para quem, apontando a fragilidade institucional de algumas Oepas, que limitaria o potencial de pesquisas locais, percebem a própria dinâmica do SNPA comprometida por "algumas debilidades na organização e na coordenação do SNPA, que fazem com que ele não funcione verdadeiramente com um sistema".

Tal coordenação não parece ser exercida efetivamente, como se acredita comprovado em estudo realizado pelo Centro de Gestão e Estudos Estratégicos (CGEE) em 2006. As Oepas, um dos três elementos do SNPA (os outros são a Embrapa e as universidades), foram encontradas desviadas para

outras atividades, atuando de forma desarticulada e sem efetiva coordenação dos poucos projetos de investigação em execução. Muitos deles são sobrepostos e concorrentes entre si, distantes das demandas da grande produção e sujeitos à descontinuidade, em função das limitações de orçamento e de injunções políticas (Centro..., 2006:8).

O estudo sinaliza que a Embrapa tomou para si atribuições que seriam das Oepas (solução de problemas agropecuários específicos de estados), deixando-as desamparadas - isso já na visão das Oepas. Mesmo dispondo de 593 pesquisadores efetivos e bem titulados (Centro..., 2006:65), as Oepas teriam se visto sem os repasses da Embrapa ${ }^{14}$ e dos governos estaduais, convencidos que a Embrapa poderia, per se, atender à demanda de pesquisa. A Embrapa, por outro lado, teria sido conivente com a situação a lhe facilitar oportunidades para maior captação e retenção de recursos. Tal quadro perdura há mais de 10 anos, período no qual somente se agravou a situação das Oepas, desde o momento em que os recursos para a pesquisa agropecuária refluíram e a Embrapa "ficou privada de manter o apoio que concedia a Oepas". ${ }^{15}$ Dissipou-

\footnotetext{
${ }^{13}$ Nos balanços sociais da Embrapa de 2007 e de 2008 não se encontrou uma menção sequer ao SNPA.

${ }^{14}$ De 2001 a 2005, a Embrapa respondeu por 1\% (14,2 milhões de reais atualizados para 2006), nove vezes menos do que as Oepas conseguem gerar de recursos próprios.

${ }^{15}$ Até então, a Embrapa vinha devotando recursos, cooperativamente, com os governos estaduais para a criação das empresas estaduais de pesquisa. Financiava pesquisas, cedia pesquisadores
} 
se a divisão de funções, exigência típica de qualquer sistema: o SNPA existiria legalmente, mas não funcionaria (Centro..., 2006:58) — onde o coordenador é tomado mais como competidor:

Vários dos pesquisadores entrevistados, entretanto, explicitaram a percepção de que a Embrapa, frequentemente, apresenta-se como um competidor e não como colaborador. E, nas oportunidades em que efetivamente ocorrem cooperações, o reconhecimento dos méritos frequentemente se distribui de forma desigual, em detrimento das Oepas. O fato concreto é que só uma Oepa mencionou manter um alto nível de cooperação com a Embrapa, como desejável seria para todas. A expressa maioria reporta um nível razoável ou baixo (Centro..., 2006:90).

Fuck e Bonacelli (2007:97) reconhecem o conflito de função: competidora/coordenadora, refletindo em relação de dominação, de subordinação (e não de parcerias, entre Embrapa e Oepas), e recomendam organizar a divisão de tarefas na pesquisa agropecuária. Se a Embrapa não exerce coordenação de fato sobre as Oepas, criadas de forma a serem enquadradas no SNPA, muito menos a faz frente às Universidades públicas, que gozam de autonomia administrativa e acesso a outras fontes de financiamento para suas pesquisas.

Todavia, a Embrapa tem mais uma oportunidade para rever sua linha de atuação, pelo menos junto às Oepas. A empresa aprovou junto ao governo federal o "Programa de fortalecimento e crescimento da Embrapa", que prevê investimentos de 914 milhões de reais. Desse volume, estão reservados $\mathrm{R} \$$ 263,6 milhões $^{16}$ a serem aplicados nas Oepas, no período de 2008 a 2010, visando apoiar a recuperação e a ampliação de seu capital físico, notadamente instalações e equipamentos de pesquisa. Para receber sua parte, cada Oepa se verá obrigada por convênio a cumprir metas e empenhar contrapartida em bens e serviços até 2010 (Embrapa, 2009c). Uma vez realizados os investimentos, caberá à Embrapa decidir pelo estabelecimento de mais convênios de pesquisa (e correspondentes repasses) para ter o poder de, em algum grau, direcionar a carteira de P\&D dessas organizações, sob pena de manutenção da situação atual.

(que ainda permanecem nessa condição) e repassava recursos para a titulação de pesquisadores das Oepas (Centro..., 2006:37).

${ }^{16}$ Esse valor corresponde, aproximadamente, ao orçamento de um ano das Oepas e é 92 vezes maior que o repasse médio anual da Embrapa (2,8 milhões, equivalente a 1\% do orçamento das Oepas), tomando como referência os valores médios do período entre 2001 e 2005. 


\subsection{Equilíbrio "fazer/saber" no campo científico agropecuário}

Reservando algum papel de menor relevância para as entidades privadas, o campo de pesquisa agropecuário brasileiro é constituído por cientistas ligados a entidades públicas federais e estaduais, empresas (Embrapa e algumas Oepas), institutos (outras Oepas) e universidades. Ao mesmo tempo que essa fonte de financiamento confere ao campo uma autonomia relativa ante o mercado, ela limita sua independência ao subordiná-lo ao atendimento de "demandas sociais". Não se deve ignorar o caráter subjetivo, manipulável e a serviço da ideologia dominante incorporado nessa construção discursiva (demanda social): social é aquela necessidade definida como tal por quem tem o poder de apontá-la - que justifica, paradoxalmente, a produção em escala (erradicação da fome) e a agricultura familiar (proteção do pequeno produtor), muito na seara do discurso.

Para se atender uma demanda, há de se entregar um produto, o que implica a necessidade de fazê-lo. Tipicamente, a necessidade de fazer, submissa ao imperativo das demandas sociais, concederia valor: 1) à gestão ativa em C\&T, maximizadora da eficiência, 2) à verticalização da pesquisa, 3) à pesquisa aplicada, 4) à difusão, à transferência e à medição dos impactos de tecnologias, 5) à inovação, 6) a uma visão de urgência, 7) ao reinvestimento obtido da apropriação excludente do resultado da pesquisa e 8) à governabilidade - requerendo de seu cientista profissional habilidade administrativa, aptidão para a liderança, espírito empreendedor e capacidade para gerar e transformar conhecimentos para criar ou adaptar tecnologias.

O modelo "concentrado" de Cardilho (2007) incorpora algumas das características listadas em detrimento das características de seu modelo "difuso", mais apropriado a outro imperativo, o da ciência pura: entendimento não finalístico do mundo natural e social. O imperativo da ciência pura favoreceria a autonomia dos pesquisadores, sua especialização, a pesquisa básica, a invenção, a apropriação universal dos resultados e não reconhecimento de prazos. Sob esse imperativo a ciência se validaria e se voltaria a si mesma (Quental, Gadelha e Fialho, 2000).

A dosagem entre as necessidades fazer/saber é da ordem do sujeito - sua propensão à pesquisa básica ou aplicada, à invenção ou à inovação, como em Bourdieu (2004) —, sobre o qual recaem os estímulos organizacionais, institucionais e mesmo da disciplina a que ele está afeito. É da ordem do sujeito, na medida em que é ele quem identifica a oportunidade (uma lacuna) e os recursos requeridos (ativos físicos e competências), negocia parcerias, propõe projetos, executa a pesquisa e emite os relatórios. Mas tais ações são, 
ao mesmo tempo, facilitadas e limitadas pela estrutura, pelos valores compartilhados, pelas pressões das organizações de pesquisa e de fomento, e dependentes de sua autonomia, de pressões externas ao campo - capazes de gerar padrões e regularidades observadas por Araújo (2008).

Não parece de grande risco afirmar que a Embrapa defende posições caras ao imperativo do fazer (do qual o Relatório Social é a evidência mais visível). A consequência disso seria tão maior quanto maior for a projeção da Embrapa sob o campo. Os componentes científico e publicitário dessa imagem foram explorados nas seções precedentes. Carecem ainda algumas considerações de ordem econômica. O ponto de máximo orçamentário da Embrapa aconteceu em 1996, quando a empresa assegurou para si 1,46 bilhão de reais, em valores atualizados. Depois de sete anos de declínio, quando as verbas foram gradualmente minguando para se limitar a 0,9 bilhão em 2003, a empresa vem conseguindo recompor as transferências recebidas do Tesouro federal e prevê valores recordes a partir de 2010, reforçados pelos montantes previstos para o Programa de Fortalecimento e Crescimento da Embrapa, aprovado em 2008 pelo governo (Embrapa, 2009c). Se confirmadas as expectativas, e desde que não se aumente a proporção de gastos fixos e investimento de capital, a empresa terá maior volume de recursos a serem destinados a projetos de pesquisa, aumentando seu poder de influência sobre os demais agentes do campo de pesquisa da agropecuária, a serem cooptados via parcerias - onde cabe lembrar, considerando os termos dos editais lançados em 2009, que a Embrapa reserva para si: 1) a posição de liderança dos projetos (exceto aqueles mediados pelo Consórcio Brasileiro de Pesquisa e Desenvolvimento do Café); e 2) a medição do mérito das propostas em função do alinhamento dessas com a estratégia institucional da empresa. Esse poder é ainda reforçado quando mais a Embrapa se credencia como formuladora ou executora de políticas públicas (Fuck, 2005; Fuck et al., 2007; Guedes e Marinho, 2006), ação-alvo do MGE da Embrapa, condicionada pela construção de uma imagem de excelência institucional (Araújo, 2000).

Tal imagem institucional, respaldada em prestígio derivado de competência científica e amplificado por doses contínuas de marketing jornalístico e científico aliado ao poder econômico, suporta as ações propositais da Embrapa para alterar o campo de jeito a esse se subordinar ao imperativo do fazer e daí ser mais favorável e coerente com a estratégia da Embrapa, diante do propósito de legitimação da empresa no campo científico e junto à sociedade em anteposição aos demais agentes, posicionados desfavoravelmente ante o desequilíbrio fazer/saber. 
Contudo, a resistência se faz presente e de forma insidiosa, à medida que os pesquisadores da própria Embrapa são continuamente cooptados pelo imperativo do saber, valorizado nas universidades. Esse contágio se dá durante a formação acadêmica e nos contatos frequentes quando retornam às universidades, já na capacidade de orientadores de teses e dissertações e nas situações de pesquisa em parceria. Uma constatação desse contágio foi explorada por Gastal (1997), que investigou o "desejo" manifestado por alguns pesquisadores da Embrapa em aumentar seu tempo dedicado à pesquisa básica. Para Gastal (1997), esse desejo é uma influência exercida pelo campo científico sobre a forma como o pesquisador da Embrapa percebe a realidade para a qual estaria trabalhando - capaz de explicar, pelo menos de forma parcial, as manifestações de sofrimento, descrença e perturbação ante o dirigismo da empresa, discorridas na seção 2 .

\section{Conclusão}

As evidências apresentadas no trabalho ensejam a proposição de um complemento ao capital social proposto por Bourdieu (2004). Tanto quanto ele, admite-se que o capital social de uma entidade científica seria composto de duas parcelas: o capital em prestígio e o capital institucional (aquele ligado à ocupação de posições de caráter burocrático e político, portanto, de poder - intrusão que tem sua gênese na cessão de parte da autonomia do campo, devido a sua necessidade de financiamento para cobrir o custo da ciência). Mas em acréscimo a Bourdieu, este estudo liga o capital em prestígio às credenciais científicas objetivas (medidas pela bibliometria e pela sociometria) do agente ajustadas por um fator, positivo no caso da Embrapa, que cria uma representação, uma imagem, diferente - maior ou menor, e sempre relativa aos demais agentes - daquela objetiva, mas admitida como real pelo campo e, mais ainda, pelos alocadores de recurso.

Afinal, mediante a promoção de acontecimentos e a produção de notícias, as entidades inserem-se no espaço público, construindo não apenas uma representação de si mesmas como também a realidade do campo em que atuam; onde a justificativa de prestar contas à sociedade é pretexto para angariar aliados comprometidos com a manutenção da entidade diante dos concorrentes e para legitimar preferências (Monteiro, 2005:142).

Se no imaginário a Embrapa responderia por $50 \%$ da pesquisa agropecuária brasileira (como sugere o Mapa) e se os dados encontrados para a soja e o para o café (culturas que respondem por um quarto do PIB agropecuário 
do Brasil) são válidos e extensíveis aos demais produtos do setor, o ajuste no capital de prestígio montaria a três vezes - o que indica a dimensão da eficiência da comunicação da empresa, preocupada simultaneamente em: 1) posicionar a Embrapa como a única capaz de lidar eficientemente com o atendimento das demandas sociais; 2) valorizar a necessidade de fazer frente à de saber, alterando as regras do jogo para favorecer a estratégia da empresa, mesmo que isso implique um convite para a redução da autonomia do campo; e 3) apresentar seu modelo de gestão - fortemente calcado em poder disciplinar - como o mais apropriado.

Na linha de Foucault (1977), tais ações deveriam provocar resistências, mas elas são difusas, tanto internamente quanto no campo científico, manifestadas na forma de uma percepção de que as coisas não são bem como se apresentam - e não ensejam ações orquestradas e suficientes para fazer frente à comunicação empresarial da entidade que, afinal, é concorrente, mas também é aquela que congrega pesquisadores parceiros e colegas de banco na academia, e ainda possuidora do mandato institucional de coordenação e de poder econômico. Dentro da empresa, a resistência também é passiva, com reflexo na ordem da insatisfação (sofrimento) do empregado diante da organização do trabalho contraditória que estimula a parceria, mas mede o esforço individual.

De relevante, é a evidência do poder da comunicação, não só capaz de legitimar a estratégia da Embrapa, mas legitimar a si mesmo em um campo de cientistas positivistas e não equipados para se estender em considerações mais críticas sobre as regras do jogo que reforçam e reproduzem ao aceitar participar.

Por fim, cabe a ressalva de que, mesmo não tendo o propósito de questionar a competência científica da Embrapa, foi necessário tentar inferi-la relativamente a outras entidades focando duas das 64 áreas (culturas) relevantes da agropecuária brasileira. As indicações apresentadas devem ser tratadas dentro dessa limitação da pesquisa.

\section{Referências}

AMARAL, J.A.B. et al. IsoEmbrapa: perspectivas na busca pela excelência na gestão da Embrapa. In: CONGRESSO ABIPTI 2008, 2008, Campina Grande. Anais..., 2008. p. 1-15.

ARAÚJO, M. Resultados do projeto de modelo de gestão estratégica da Embrapa. In: V Congreso Internacional del CLAD sobre la Reforma del Estado y de la Administración Pública, V, 2000, Santo Domingo. Anais..., 2000. 
ARAÚJO, U.P. Relação agência e estrutura em redes colaborativas. 2008. 281 f. Tese (doutorado em administração) — Universidade Federal de Lavras, Lavras, 2008.

ÁVILA, A.F.D. et al. Avaliação dos impactos das tecnologias geradas pela Embrapa. Revista de Política Agrícola, v. 15, p. 86-101, 2005.

BERNARDI, A.C.C. et al. Análise e melhoria do processo de avaliação dos impactos econômicos, sociais e ambientais de tecnologias da Embrapa Pecuária Sudeste. In: CONVIBRA - CONGRESSO VIRTUAL BRASILEIRO DE ADMINISTRAÇÃO, 2008. Anais..., 2008.

BIN, A. Agricultura e meio ambiente: contexto e iniciativas da pesquisa pública. 2004. 169 f. Dissertação (mestrado em política científica) - Universidade de Campinas, Campinas, 2004.

BORGES FILHO, E.L. Da redução de insumos agrícolas à agroecologia. 2005. 289 f. Tese (doutorado em economia aplicada) - Universidade de Campinas, Campinas, 2005.

BOURDIEU, P. Os usos sociais da ciência: por uma sociologia clínica do campo científico. São Paulo: Editora Unesp, 2004.

BRASIL. Decreto no 2.291, de 4 de agosto de 1997. Aprova o Estatuto da Empresa Brasileira de Pesquisa Agropecuária. Diário Oficial da União, n. 148, 5 ago. 1997.

. Ministério da Ciência e da Tecnologia. Indicadores nacionais de ciência e tecnologia. Brasília: MCT, 2007.

. Agronegócio brasileiro: uma oportunidade de investimento. Disponível em: <www.agricultura.gov.br/>. Acesso em: 15 abr. 2009.

BRITO, M.J. et al. Os dilemas do processo de mudança em uma organização pública. Organizações e Sociedade, Salvador, v. 9, p. 77-97, 2002.

CÂMARA, R.H. Análise comparativa entre as carreiras de pesquisa e de suporte à pesquisa na Embrapa: o enfoque da psicodinâmica. 2007. 168 f. Dissertação (mestrado em gestão social e trabalho) — Universidade de Brasília, Brasília, 2007.

CAPPELLE, M.C.A; MELO, M.C.O.; BRITO, M.J.M. Uma análise da dinâmica do poder e das relações de gênero no espaço organizacional. RAE Eletrônica, v. 3, n. 22, jul./dez. 2004.

CARDILHO, M.F. A Embrapa e a Agroenergia: plano, discurso e imagem para novo modelo de desenvolvimento. 2007. 192 f. Dissertação (mestrado em desenvolvimento sustentável) — Universidade de Brasília, Brasília, 2007.

CARVALHO, S.M.P.; SALLES-FILHO, S.L.M.; PAULINO, S.R. Propriedade intelectual e organização de P\&D vegetal. Revista de Economia e Sociologia Rural, v. 45, p. 9-26, 2007. 
CENTRO DE GESTÃO DE ESTUDOS ESTRATÉGICOS (CGEE). Estudo sobre o papel das Organizações Estaduais de Pesquisa Agropecuária OEPAs. Brasília: CGEE, 2006. CONSELHO NACIONAL DE DESENVOLVIMENTO CIENTÍFICO E TECNOLÓGICO (CNPq). Banco de dados e estatísticas. Disponível em: <www.cnpq.br>. Acesso em: 15 abr. 2009.

COORDENAÇÃO DE APERFEIÇOAMENTO DE PESSOAL DE NÍVEL SUPERIOR (CAPES). Estatísticas da pós-graduação. Disponível em: <www.capes.gov.br>. Acesso em: 15 abr. 2009.

DE'CARLI, C.R. Embrapa: precursora da parceria público-privada no Brasil. 2005. 155 f. Dissertação (mestrado em desenvolvimento sustentável) - Universidade de Brasília, Brasília, 2005.

EMBRAPA. Política de comunicação. 2. ed. Brasília: Embrapa, 2002.

. Missão e atuação. Disponível em: <www.Embrapa.br/a_Embrapa/atuacao> . Acesso em: 29 abr. 2009a.

. Balanço social da pesquisa agropecuária brasileira 1998. Versão impressa de 2009, com dados de 2008. Brasília: Embrapa, 2009b.

. PAC Embrapa: fortalecendo a pesquisa agropecuária nacional — realizações 2008, ano 1. Brasília: Embrapa Informação Tecnológica, 2009c.

FOUCAULT, M. Discipline and punish: the birth of the prison. New York: Panteon, 1977.

FREEMAN, L.C. The development of social network analysis: a study in the sociology of science. Vancouver: Empirical Press, 2004.

FUCK, M.P. Funções públicas e arranjos institucionais. 2005. 121 f. Dissertação (mestrado em política científica e tecnológica) - Universidade de Campinas, Campinas, 2005.

; BONACELLI, M.B.M. A necessidade de reorganização e de fortalecimento institucional do SNPA no Brasil. Revista de Política Agrícola, v. XVI, p. 88-101, 2007.

et al. P\&D de interesse público? Observações a partir do estudo da Embrapa e da Petrobras. Engevista, v. 9, p. 85-99, 2007.

GALAS, E.S.; FORTE, S.H.A.C. Fatores que interferem na implantação de um Modelo de Gestão Estratégica baseado no Balanced Scorecard. Revista Eletrônica da Administração, Porto Alegre, v. 10, n. 5, 2004.

GASTAL, M.L. A influência do campo científico na geração de tecnologias agropecuárias. 1997. 118 f. Dissertação (mestrado em sociologia) - Universidade de Brasília, Brasília, 1997. 
GUEDES, V.G.F. Mudança institucional em organização pública de ciência e tecnologia: organização do trabalho favorecendo a gestão da inovação. In: CONGRESSO DO CENTRO LATINO-AMERICANO DE ADMINISTRAÇÃO PARA O DESENVOLVIMENTO - CLAD, VI, 2001, Buenos Aires. Anais... Caracas: Clad, 2001.

et al. Publicação de artigos em periódicos internacionais. In: CONGRESSO ABIPTI 2008, 2008, Campina Grande. Anais... Brasília: Abipti, 2008.

; MARINHO, D.N.C. Organização do trabalho em instituição de P\&D e construção do conhecimento no agronegócio. Cadernos de Ciência e Tecnologia, v. 23, p. 63-93, 2006.

INSTITUTO BRASILEIRO DE GEOGRAFIA E ESTATÍSTICA (IBGE). Contas nacionais trimestrais out./dez. 2008. Indicadores IBGE: contas nacionais trimestrais, v. $4^{\circ}$ trim. 2008, p. 1-45, 2009.

JOSEPH, L.C.R. A organização, avaliação e seleção de projetos de P\&D em diferentes economias. 2001. 223 f. Tese (doutorado em ciências econômicas) — Universidade de Campinas, Campinas, 2001.

LUIZ, A.J.B.; BITENCOURT, F.O. Gestão do conhecimento na Embrapa Meio Ambiente: análise. In: CONGRESSO DA SOCIEDADE BRASILEIRA DE ECONOMIA, ADMINISTRAÇÃO E SOCIOLOGIA RURAL, XLVI. In: Anais... Rio Branco: Sober, 2008.

MENDES, P.J.V. Flexibilidade organizacional: análise de uma experiência de organização e divisão do trabalho por processo em ambiente de P\&D. 2002. 138 f. Dissertação (mestrado em engenharia mecânica) - Universidade de Campinas, Campinas, 2002.

MONTEIRO, G.F. Marketing científico ou comunicação pública? Por que vale a pena estar na mídia? Comunicação \& Estratégia, v. 2, n. 2, jul. 2005.

MONTEIRO, R.C.; RODRIGUES, G.S. A system of integrated indicators for socioenvironmental assessment and eco-certification in agriculture - Ambitec-Agro. Journal of Technology Management \& Innovation, v. 1, p. 47-59, 2006.

MORGAN, G. Imagens da organização. São Paulo: Atlas, 2007.

NOOY, W.; MRVAR, A.; BATAGELJ, V. Exploratory social network analysis with Pajek. London: Cambridge Press, 2006.

PENTEADO, R. Aplicação da bibliometria na construção de indicadores sobre a produção científica da Embrapa. In: WORKSHOP BRASILEIRO DE INTELIGÊNCIA COMPETITIVA E GESTÃO DO CONHECIMENTO, 3ㅜ, 2002, São Paulo. Anais... São Paulo: SBGV, 2002. 
et al. Midiametria: análise do desempenho de uma organização na mídia com metodologias e softwares bibliométricos. Prisma.com, v. 5, p. 92-111, 2007.

PIEROZZI JÚNIOR, I. et al. Análise de dinâmica de uso e de desempenho: o caso do web site da Embrapa Monitoramento por Satélite. Ciência da Informação, Brasília, v. 32 , n. 1, p. 102-114, 2003.

PIETRAFESA, J.P.; SAUER, S. Os (des)caminhos do desenvolvimento rural brasileiro. In: ENCONTRO REGIONAL CENTRO-OESTE DA APIPSA, VI. Anais... Brasília: UnB, 1997. p. 69-119.

QUENTAL, C.; GADELHA, C.A.G.; FIALHO, B.C. O papel dos institutos públicos de pesquisa na inovação farmacêutica. Revista Brasileira de Administração Pública, Rio de Janeiro, v. 35, p. 135-161, 2000.

RODRIGUES, G.S.; CAMPANHOLA, C.; KITAMURA, P.C. Avaliação de impacto ambiental da inovação tecnológica agropecuária. Cadernos de Ciências e Tecnologia, Brasília, v. 19, n. 3, p. 349-375, 2002.

SALLES-FILHO, S. et al. Ciência, tecnologia e inovação: a reorganização da pesquisa pública no Brasil. Campinas: Editora Komedi, 2000.

SILVA, D.O. da. Linguagem científica e tecnológica no jornalismo da Embrapa: anotações sobre discursos no relise difucionista. 2007. 143 f. Dissertação (mestrado em comunicação) — Universidade Federal de Pernambuco, Recife, 2007.

SILVEIRA, R.A. da. Michel Foucault: poder e análise das organizações. Rio de Janeiro: Editora FGV, 2005.

SOUZA, G.S.; ÁVILA, A.F.D. A psicometria linear da escalagem ordinal: uma aplicação na caracterização da importância relativa de atividades de produção em ciência e tecnologia. Cadernos de Ciência \& Tecnologia, Brasília, v. 17, n. 2, p. 11-27, set./dez. 2000.

et al. Economic efficiency of Embrapa's research centers and the influence of contextual variables. Pesquisa Operacional, v. 27, p. 15-26, 2007.

UBEDA, C.L.; SANTOS, F.C.A. Os principais desafios da gestão de competências humanas em um instituto de pesquisa pública. Gestão e Produção, v. 15, p. 189199, 2008.

VEIGA, S.C. Implementação de ferramenta de gestão em organizações públicas. 2007. 85 f. Dissertação (mestrado em administração) — Universidade Federal de Viçosa, Viçosa, 2007.

VIEIRA, O.V.; OLIVEIRA, M.F. de; DOMIT, L.A. Treino e visita: experiência da 
Embrapa Soja e da iniciativa privada na transferência de tecnologia. Cadernos de Ciência e Tecnologia, v. 21, p. 265-278, 2004.

ZANINELLI, T.B.; CATARINO, M.E. Recuperação de informação no banco de dados da Embrapa Soja: estudo do Ainfo. Informação \& Informação, v. 9, p. 1-19, 2004. 